\title{
Letter \\ Evidence-based approach to intensive care unit management: need for improvement
}

\author{
Anders Ersson and Michelle Chew
}

Department of Intensive Care Medicine, Entrance 42, Level 2, Malmö University Hospital, S-20505 Malmö, Sweden

Corresponding author: Anders Ersson, anders.ersson@skane.se

Published: 25 January 2008

Critical Care 2008, 12:404 (doi:10.1186/cc6763)

This article is online at http://ccforum.com/content/12/1/404

(c) 2008 BioMed Central Ltd

See related review by Strack van Schijndel and Burchardi, http://ccforum.com/content/11/6/234

We read with great interest the contribution by Strack van Schijndel and Burchardi [1]. The topic of intensive care unit (ICU) management deserves to be highlighted as it is a most complex task to undertake. In their paper, the authors refer to Covey's Seven Habits of Highly Effective People [2], but did not distinguish between leadership and management - two fundamentally different but not mutually exclusive concepts. To paraphrase Covey [2], 'Management is a bottom line focus: How do I best accomplish ...?' whereas 'Leadership deals with the top line: What do I want to accomplish ...?'

The ICU is, as pointed out, a very stressful environment. Leadership, the provision of good working conditions, a supporting and team-building environment, adequate resources for individual assignments and scientific projects, and good utilisation of human resources are certainly an art in itself. The need for a more focused approach to ICU management is highlighted in recent papers [3,4], where a high frequency of burnout among ICU personnel was reported. This alarming finding was also accompanied by a high desire among ICU staff to leave their work, indicating that immediate actions are needed to adapt the critical care organisation to new professional demands, to the increasing workload and to increasing complexity.
In the light of this and the well recognised shortage of ICU staff [5], it is paramount that the leadership and management of ICUs are given more recognition in order to enhance recruitment, to promote staff retention and to increase job satisfaction, while maintaining quality and effectiveness. Defining the requirements and skills of future ICU directors is an important step in this process.

Modern critical care is rapidly developing into a profession where traditional boundaries between clinical specialities no longer apply. Its management must be performed in close synchrony to clinical activities, with preparedness for policy changes and capacity for multiprofessional liaison between physicians, nursing staff and personnel from other specialities.

Typically, directors are recruited on clinical and scientific merits. This does not, however, necessarily assure that the candidate has the required leadership and managing skills. Finding oneself inadequately equipped with the necessary tools and training is very unfortunate and uncomfortable for an otherwise highly competent individual, and not least for staff and patients alike. More effort and research are needed to define the skills required for leading and managing an ICU, and it is appropriate to develop training programmes where those capabilities are enhanced and trained.

\section{Authors' response \\ Rob JM Strack van Schijndel and Hilmar Burchardi}

We are pleased with the positive reaction from our Swedish colleagues, stressing the importance of leadership and management in the ICU. Our contribution was meant as a framework, rather than an in-depth coverage of these important issues.
We agree with their comment on the distinction between management and leadership. As pointed out by Ersson and Chew, the importance of creating an environment where people can keep their motivation and can function with satisfaction is one of the most challenging tasks for the leader

$\mathrm{ICU}=$ intensive care unit. 
to accomplish. This is also our conviction. Apart from the extra references provided in their letter, the two-factor theory as formulated by Frederick Herzberg and colleagues might also be of value to readers interested in this subject [6]. They postulated that certain factors in the workplace result in job satisfaction (motivators), while other factors do not motivate if present, but if absent they will result in dissatisfaction. The latter group is called hygiene factors - because, like hygiene will not make you healthy, the absence of hygiene can cause health deterioration. We believe that dissatisfaction among ICU workers is more often a problem of these hygiene factors than the absence of motivators.

We fully agree that more effort and research in management and leadership issues in the ICU can increase the adequacy, skills and thus job satisfaction of ICU directors.

\section{Competing interests}

The authors declare that they have no competing interests.

\section{References}

1. Strack van Schijndel RJM, Burchardi H: Bench-to-bedside review: Leadership and conflict management in the intensive care unit. Crit Care 2007, 11:234.

2. Covey SR: The Seven Habits of Highly Effective People. New York: Franklin Covey Co. Fireside; 1990.

3. Embriaco N, Azoulay E, Barrau K, Kentish N, Pochard F, Loundou A, Papazian L: High level of burnout in intensivists. Am J Respir Crit Care Med 2007, 175:686-692.

4. Thomas N: Resident burnout. JAMA 2004, 292:2880-2889.

5. Kelley MA, Angus D, Chalfin DB, Crandall ED, Ingbar D, Johanson W, Medina J, Sessler CN, Vender JS: The critical care crisis in the United States. Chest 2004, 125:1514-1517.

6. Herzberg F, Mausner B, Snyderman BB: The Motivation to Work. New York: John Wiley; 1959. 